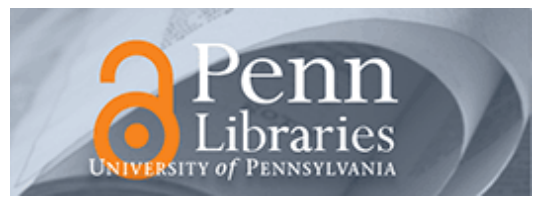

University of Pennsylvania

ScholarlyCommons

Finance Papers

Wharton Faculty Research

2002

\title{
Asset Pricing With Heterogeneous Consumers and Limited Participation: Empirical Evidence
}

Alon Brav

George M. Constantinides

Christopher C. Geczy

University of Pennsylvania

Follow this and additional works at: https://repository.upenn.edu/fnce_papers

Part of the Finance and Financial Management Commons

\section{Recommended Citation}

Brav, A., Constantinides, G. M., \& Geczy, C. C. (2002). Asset Pricing With Heterogeneous Consumers and Limited Participation: Empirical Evidence. Journal of Political Economy, 110 (4), 793-824.

http://dx.doi.org/10.1086/340776

This paper is posted at ScholarlyCommons. https://repository.upenn.edu/fnce_papers/408

For more information, please contact repository@pobox.upenn.edu. 


\title{
Asset Pricing With Heterogeneous Consumers and Limited Participation: Empirical Evidence
}

\author{
Abstract \\ We present evidence that the equity premium and the premium of value stocks over growth stocks are \\ consistent in the 1982-96 period with a stochastic discount factor calculated as the weighted average of \\ individual households' marginal rate of substitution with low and economically plausible values of the \\ relative risk aversion coefficient. Since these premia are not explained with an SDF calculated as the per \\ capita marginal rate of substitution with a low value of the RRA coefficient, the evidence supports the \\ hypothesis of incomplete consumption insurance. We also present evidence that an SDF calculated as \\ the per capita marginal rate of substitution is better able to explain the equity premium and does so with \\ a lower value of the RRA coefficient, as the definition of asset holders is tightened to recognize the limited \\ participation of households in the capital market.

\section{Disciplines} \\ Finance and Financial Management
}




\title{
Asset Pricing with Heterogeneous Consumers and Limited Participation: Empirical Evidence
}

\author{
Alon Brav \\ Duke University \\ George M. Constantinides \\ University of Chicago and National Bureau of Economic Research \\ Christopher C. Geczy \\ University of Pennsylvania
}

\begin{abstract}
We present evidence that the equity premium and the premium of value stocks over growth stocks are consistent in the 1982-96 period with a stochastic discount factor calculated as the weighted average of individual households' marginal rate of substitution with low and economically plausible values of the relative risk aversion coefficient. Since these premia are not explained with an SDF calculated as the per capita marginal rate of substitution with a low value of the RRA coefficient, the evidence supports the hypothesis of incomplete consumption insurance. We also present evidence that an SDF calculated as the per capita marginal rate of substitution is better able to explain the equity premium and does so with a lower value of the RRA coefficient, as the definition of asset holders is tightened to recognize the limited participation of households in the capital market.
\end{abstract}

We thank John Cochrane, Jonathan Parker, Geert Rouwenhorst, Chris Telmer, Annette Vissing-Jørgensen, Wolf Weber, Simon Wheatley, two anonymous referees, and participants at the American Finance Association conference, Asia-Pacific video seminar series, Atlanta Fed, Centre for Interuniversity Research and Analysis on Organizations conference in Montreal, the European Financial Management Association conference, London School of Economics, NBER Asset Pricing conference, Princeton University, and Yale University for helpful comments.

[Journal of Political Economy, 2002, vol. 110, no. 4]

(c) 2002 by The University of Chicago. All rights reserved. 0022-3808/2002/11004-0003\$10.00 


\section{Introduction and Summary}

In a representative-consumer exchange economy, one set of implications of the equilibrium are the Euler equations of per capita consumption. In tests of the conditional Euler equations of per capita consumption, Hansen and Singleton (1982), Ferson and Constantinides (1991), Hansen and Jagannathan (1991), and others reject the model.

A related set of equilibrium implications that take into account both the Euler equations of per capita consumption and the market-clearing conditions are the predictions of a calibrated economy on the unconditional mean and standard deviation of the market return and the riskfree rate. Mehra and Prescott (1985) demonstrate that the equilibrium of a reasonably parameterized representative-consumer exchange economy is able to furnish a mean annual premium of equity return over the risk-free rate of, at most, 0.35 percent. This contrasts with the historical premium of 6 percent in U.S. data. Furthermore, as stressed in Weil (1989), the equilibrium annual risk-free rate of interest is consistently too high, about 4 percent, as opposed to the observed 1 percent in U.S. data.

Several generalizations of essential features of the model have been proposed to mitigate its poor performance. They include alternative assumptions on preferences (e.g., Abel 1990; Constantinides 1990; Epstein and Zin 1991; Ferson and Constantinides 1991; Benartzi and Thaler 1995; Daniel and Marshall 1997; Campbell and Cochrane 1999, 2000; Boldrin, Christiano, and Fisher 2001), modified probability distributions to admit rare but disastrous marketwide events (Mehra and Prescott 1988; Rietz 1988), incomplete markets (e.g., Bewley 1982; Mehra and Prescott 1985; Mankiw 1986; Telmer 1993; Lucas 1994; Constantinides and Duffie 1996; Heaton and Lucas 1997, 2000; Storesletten, Telmer, and Yaron 1999; Krebs 2000), market imperfections (e.g., Aiyagari and Gertler 1991; Danthine, Donaldson, and Mehra 1992; Brav and Geczy 1995; He and Modest 1995; Bansal and Coleman 1996; Heaton and Lucas 1996; Luttmer 1996; Basak and Cuoco 1998; Alvarez and Jermann 2000; Constantinides, Donaldson, and Mehra 2002), and the survival bias of the U.S. capital markets. ${ }^{1}$ Cochrane and Hansen (1992), Kocherlakota (1996), and Cochrane (1997) provide excellent surveys of this literature.

Full consumption insurance implies that heterogeneous consumers are able to equalize, state by state, their marginal rate of substitution. Therefore, the equilibrium in a heterogeneous-consumer, full-information economy is isomorphic in its pricing implications to the equi-

\footnotetext{
${ }^{1}$ However, Jorion and Goetzmann (1999, table 6) find that the average real capital gain rate of a U.S. equities index exceeds the average rate of a global equities index that includes markets that both have and have not survived by merely 1 percent per year.
} 
librium in a representative-consumer, full-information economy if consumers have von Neumann-Morgenstern preferences (see Wilson 1968; Constantinides 1982). The strong assumption of full consumption insurance is indirectly built in asset pricing models in finance and neoclassical macroeconomic models through the assumption of the existence of a representative consumer.

Bewley (1982), Mehra and Prescott (1985), and Mankiw (1986) suggest the potential of enriching the asset pricing implications of the representative-consumer paradigm by relaxing the assumption of complete consumption insurance. ${ }^{2}$ With the exception of Constantinides and Duffie (1996), the extant research suggests that the potential enrichment is largely illusory. ${ }^{3}$ Constantinides and Duffie find that incomplete consumption insurance enriches substantially the implications of the representative-consumer model. Their main result is a proposition demonstrating, by construction, the existence of household income processes, consistent with a given aggregate income process such that equilibrium security and bond price processes match the given security and bond price processes. Since the proposition demonstrates the existence of equilibrium in frictionless markets, it implies that the Euler equations of household (but not necessarily of per capita) consumption must hold.

The first goal of our paper is to examine the asset pricing implications of the relaxation of the assumption of complete consumption insurance. The basis of our empirical investigation is the set of Euler equations of household consumption, as opposed to the Euler equations of per capita consumption. ${ }^{4}$ The set of Euler equations of household consumption imply that any household's marginal rate of substitution and any weighted sum thereof are a valid stochastic discount factor (SDF). Since individual consumption data are reported with substantial error, it is

${ }^{2}$ There is an extensive literature on the hypothesis of complete consumption insurance; see Cochrane (1991), Mace (1991), Altonji, Hayashi, and Kotlikoff (1992), and Attanasio and Davis (1996).

${ }^{3}$ Telmer (1993) and Lucas (1994) calibrate economies in which consumers face uninsurable income risk and borrowing or short-selling constraints. They conclude that consumers come close to the complete-markets rule of complete risk sharing, although consumers are allowed to trade in just one security in a frictionless market. Aiyagari and Gertler (1991) and Heaton and Lucas $(1996,1997)$ add transaction costs or borrowing costs or both and reach a similar negative conclusion, provided that the supply of bonds is not restricted to an unrealistically low level. The primary reason why Constantinides and Duffie (1996) find that incomplete consumption insurance substantially enriches the asset pricing implications of the representative-consumer model is that they allow the idiosyncratic income shocks to be persistent and their conditional variance to be related to the state variables in a particular way, in contrast to earlier work that restricts the idiosyncratic income shocks to being transient and homoscedastic.

${ }^{4}$ Related studies include those by Jacobs (1999), who studies the Panel Study of Income Dynamics (PSID) database on food consumption, and Cogley (2002) and Vissing-Jørgensen (2002; this issue), who study the Consumer Expenditure Survey (CEX) database on broad measures of consumption. 
difficult to test directly the hypothesis that each household's marginal rate of substitution is a valid SDF. Therefore, we test the hypothesis that the SDF given by the equally weighted sum of the households' marginal rates of substitution is a valid SDF.

The bulk of our tests are on the premium of the value-weighted and the equally weighted market portfolio return over the risk-free rate. We do not reject the hypothesis that the equally weighted sum of the households' marginal rates of substitution is a valid SDF with a relative risk aversion (RRA) coefficient between two and four. We perform several robustness tests that reinforce the conclusion. An RRA coefficient between two and four is economically plausible.

We investigate the properties of the cross-sectional distribution of the household consumption growth that drive the SDF. We find that a Taylor expansion of the SDF that captures the skewness, in addition to the mean and variance, of the cross-sectional distribution explains the equity premium. However, a Taylor expansion of the SDF that captures the mean and variance (but not the skewness) of the cross-sectional distribution of the household consumption growth does not fare as well. A Taylor expansion of the SDF, in terms of the logarithm of the household consumption growth, that captures the mean, variance, and skewness of the cross-sectional distribution of the household consumption growth does not fare well either. These results underscore the importance of the skewness, combined with the first two moments of the cross-sectional distribution. They also suggest that empirical findings based on loglinearized Euler equations of individual households should be treated with caution.

The second goal of our paper is to reexamine the asset pricing implications of the limited participation of households in the capital markets. Mankiw and Zeldes (1991), Blume and Zeldes (1993), and Haliassos and Bertaut (1995) present evidence of limited participation of households in the capital markets. Specifically, they observe that only a small fraction of individuals and households hold equities either directly or indirectly. Furthermore, Mankiw and Zeldes calculate the per capita food consumption of a subset of households, designated as asset holders according to a criterion of asset holdings above some threshold. They find that the implied RRA coefficient decreases as the threshold is raised. ${ }^{5}$ Attanasio and Weber (1995) argue that food consumption is a dubious proxy for total consumption.

\footnotetext{
${ }^{5}$ Brav and Geczy (1995) provide the first confirmation of the Mankiw and Zeldes (1991) results by using per capita consumption of nondurables and services reconstructed from the CEX database. Section V of the current paper contains an updated and extended version of Brav and Geczy (1995) and subsumes the 1995 draft. Related results are presented in the paper by Attanasio, Banks, and Tanner (2002; this issue), who study the U.K. Family Expenditure Survey database, and Vissing-Jørgensen (2002; this issue), who studies the CEX database.
} 
We recognize the fact that only a subset of households is marginal in the stock market by defining as asset holders the subset of households that report total assets exceeding a certain threshold value ranging from $\$ 0$ to $\$ 40,000$. From the subset of households defined as asset holders, we express the SDF in terms of the per capita growth rate and test whether this SDF explains the equity premium. We find that the model is better able to explain the equity premium and does so with a decreasing value of the RRA coefficient as the definition of asset holders is tightened. The results are sensitive to empirical design.

We also report the correlation of the per capita consumption growth with the equity premium. There is a pattern of increasing correlation as the definition of asset holders is tightened. These results are in line with earlier results reported by Mankiw and Zeldes (1991) and Brav and Geczy (1995). In summary, we find some evidence that the SDF driven by the per capita consumption growth can explain the equity premium with a relatively high value of the RRA coefficient, once we recognize the fact that only a subset of households is marginal in the stock market.

All the tests reported so far, whether under the hypothesis of complete or incomplete consumption insurance, focus on explaining the equity premium. Finally, we report results of tests with the unconditional Euler equation on the excess return of high-book-to-market "value" stocks over low-book-to-market "growth" stocks. This may be viewed as a test of the conditional Euler equation, where the attribute of book-to-market is the conditioning variable. In addition, as in the market portfolio, both parts of this spread between value and growth are typically available to investors through brokerage and retirement accounts in the form of managed fund investments. (We do not attempt to explain the premium of small- vs. large-capitalization stocks because there is no size premium in our sample period.) We conclude that the SDF implied by a model of incomplete consumption insurance is consistent with the value premium whereas the SDF implied by a model of complete consumption insurance is not. The results reinforce our earlier findings on the equity premium.

The paper is organized as follows. In Section II, we discuss the theory that motivates the empirical investigation. The data sources, the data selection procedure, and summary statistics are described in Section III. In Section IV, we present the empirical results on the equity premium under the hypothesis of incomplete consumption insurance. In Section $\mathrm{V}$, we present the empirical results on the equity premium under the hypothesis of complete consumption insurance and examine the extent to which the equity premium is better explained by taking into consideration the limited participation of the households in the capital markets. In Section VI, we report evidence that the premium of value stocks over growth stocks is consistent with Euler equations of consumption, 
under the hypothesis of incomplete consumption insurance. In Section VII, we provide extensions and concluding remarks.

\section{The Model}

\section{A. The Economy and Equilibrium}

We make conventional assumptions about the markets and preferences in order to focus on our stated dual goal of investigating the pricing implications of the incompleteness of markets that insure against idiosyncratic income shocks and the limited participation of households in the capital markets.

We consider a set of households, $i=1, \ldots, I$, that participate in the capital markets. We assume that these households trade in perfect capital markets, without frictions, short-sale restrictions, or taxes. They trade a set of securities subscripted by $j=1, \ldots, J$, with total return $R_{j, t}$ between dates $t-1$ and $t$. We assume that the households have time- and stateseparable von Neumann-Morgenstern homogeneous preferences

$$
E\left[(1-\alpha)^{-1} \sum_{t=0}^{\infty} \beta^{t}\left(c_{i, t}^{1-\alpha}-1\right) \mid F_{0}\right],
$$

where $\alpha, \alpha>0$, is the constant RRA coefficient; $\beta$ is the constant subjective discount factor; $c_{i, t}$ is the dollar consumption of the $i$ th household at date $t$; and $F_{t}$ is the date $t$ information set that is common across the households.

In equilibrium, we obtain the set of $I \times J$ Euler equations of consumption between dates $t-1$ and $t$ :

$$
E\left[\beta g_{i, t}^{-\alpha} R_{j t} \mid F_{t-1}\right]=1, \quad i=1, \ldots, I, j=1, \ldots, J,
$$

where $g_{i, t}=c_{i, t} / c_{i, t-1}$ is the consumption growth of the $i$ th household.

\section{B. $\quad$ Stochastic Discount Factors}

A stochastic discount factor or pricing kernel, $m_{t}$, is defined by the property

$$
E\left[m_{t} R_{j, t} \mid F_{t-1}\right]=1, \quad j=1, \ldots, J .
$$

We note that each household's marginal rate of substitution, $\beta\left(c_{i, t} / c_{i, t-1}\right)^{-\alpha}$, is a valid SDF, and any weighted sum of the households' marginal rates of substitution is a valid SDF also. Since individual consumption data are reported with substantial error, it is difficult to test directly the hypothesis that each household's marginal rate of substitution is a valid SDF.

We may be able to mitigate the observation error in reported house- 
hold consumption by testing the hypothesis that the equally weighted sum of the households' marginal rates of substitution is a valid SDF:

$$
m_{t}=\beta\left[I^{-1} \sum_{i=1}^{I}\left(\frac{c_{i, t}}{c_{i, t-1}}\right)^{-\alpha}\right] .
$$

This SDF is still susceptible to observation error because each term in the sum is raised to a high power if the RRA coefficient is high.

We expand equation (4) as a Taylor series up to cubic terms. We obtain the following approximation for the SDF:

$$
\begin{aligned}
m_{t}= & \beta g_{t}^{-\alpha}\left[1+\frac{1}{2} \alpha(\alpha+1) I^{-1} \sum_{i=1}^{I}\left(\frac{g_{i, t}}{g_{t}}-1\right)^{2}\right. \\
& \left.-\frac{1}{6} \alpha(\alpha+1)(\alpha+2) I^{-1} \sum_{i=1}^{I}\left(\frac{g_{i, t}}{g_{t}}-1\right)^{3}\right]
\end{aligned}
$$

in terms of the cross-sectional mean, $g_{t}=I^{-1} \sum_{i=1}^{I_{i}} g_{i, v}$ variance, $I^{-1} \sum_{i=1}^{I}\left[\left(g_{i, t} / g_{t}\right)-1\right]^{2}$, and skewness, $I^{-1} \sum_{i=1}^{I}\left[\left(g_{i, t} / g_{t}\right)-1\right]^{3}$, of the consumption growth rate. We may further mitigate the observation error if the estimation of these cross-sectional moments is less susceptible to observation error than the SDF in equation (4). In testing the hypothesis that the SDF is given by equation (5) against the alternative hypothesis that the SDF is given by equation (4), we also investigate whether the cross-sectional variance and skewness of the consumption growth rate capture most of the cross-sectional variation.

If we expand equation (4) as a Taylor series up to quadratic terms, we obtain the SDF

$$
m_{t}=\beta g_{t}^{-\alpha}\left[1+\frac{1}{2} \alpha(\alpha+1) I^{-1} \sum_{i=1}^{I}\left(\frac{g_{i, t}}{g_{t}}-1\right)^{2}\right]
$$

in terms of the average consumption growth rate and the cross-sectional variance of the consumption growth rate. In testing the hypothesis that the SDF is given by equation (6), we investigate whether the crosssectional variance of the consumption growth rate alone captures most of the cross-sectional variation.

If we assume that the idiosyncratic income shocks are multiplicative and independently and identically distributed (i.i.d.) lognormal, then 
Constantinides and Duffie (1996) show that the SDF in equation (4) simplifies to

$$
\begin{aligned}
m_{t}= & \beta\left(\frac{\sum_{i=1}^{I} c_{i, t}}{\sum_{i=1}^{I} c_{i, t-1}}\right)^{-\alpha} \exp \left\{\frac { 1 } { 2 } \alpha ( \alpha + 1 ) I ^ { - 1 } \sum _ { i = 1 } ^ { I } \left[\log \left(g_{i, t}\right)\right.\right. \\
& \left.\left.-I^{-1} \sum_{i=1}^{I} \log \left(g_{i, t}\right)\right]\right\}
\end{aligned}
$$

In testing the hypothesis that the SDF is given by equation (7), we investigate whether multiplicative and i.i.d. lognormal idiosyncratic income shocks capture most of the cross-sectional variation of the consumption growth rate. ${ }^{6}$

If a complete set of markets exists that enables households to insure against idiosyncratic income shocks, then the heterogeneous households are able to equalize, state by state, their marginal rates of substitution. Therefore, the equilibrium of a heterogeneous-household, fullinformation economy is isomorphic in its pricing implications to the equilibrium of a representative-household, full-information economy (see Constantinides 1982). In particular, the consumption growth rate is identical across households, and the SDF in equation (4) simplifies to

$$
m_{t}=\beta g_{t}^{-\alpha} \text {. }
$$

Market completeness also implies that the SDF in equation (4) simplifies to

$$
m_{t}=\beta\left(\frac{\sum_{i=1}^{I} c_{i, t}}{\sum_{i=1}^{I} c_{i, t-1}}\right)^{-\alpha} .
$$

We expect that the SDF given by equation (9) is less susceptible to observation error than the SDF given by equation (8).

Tests of the SDFs given by either one of equations (8) and (9) against the SDFs given by any of equations (4)-(7) are tests of the hypothesis of complete consumption insurance against the alternative hypothesis of incomplete consumption insurance. These tests are the focus of the paper.

\footnotetext{
${ }^{6}$ Krebs (2000) generalizes the lognormal idiosyncratic income process of consumers by introducing a process that assigns probability $p$ to an event of near personal bankruptcy: a consumer's permanent income drops close to zero with probability $p$. When the permanent income is made sufficiently close to zero in the event of near bankruptcy, the prospect of near bankruptcy does affect equilibrium prices, even if $p$ is made arbitrarily small. Then idiosyncratic income shocks can have an important effect on prices, even though we can make the covariance between the equity premium and the cross-sectional variance of $\log \left(g_{i, t}\right)$ arbitrarily small.
} 


\section{Tests of Stochastic Discount Factors}

In most of our tests, we test each candidate SDF with the unconditional Euler equation on the excess market return, $R_{M, t}-R_{F, t}$ (both the equally weighted and value-weighted), as

$$
E\left[m_{t}\left(R_{M, t}-R_{F, t}\right)\right]=0 .
$$

Specifically, we calculate the statistic $u$ as

$$
u=T^{-1} \sum_{t=1}^{T} m_{t}\left(R_{M, t}-R_{F, t}\right)
$$

and interpret it as the unexplained mean premium. ${ }^{7}$

We also test some SDFs with the unconditional Euler equation on the excess return of high-book-to-market (value) stocks over low-book-tomarket (growth) stocks, $R_{H, t}-R_{L, t}$, as $E\left[m_{t}\left(R_{H, t}-R_{L, t}\right)\right]=0$ and calculate the corresponding unexplained-premium statistic as

$$
u=T^{-1} \sum_{t=1}^{T} m_{t}\left(R_{H, t}-R_{L, t}\right) .
$$

This may be viewed as a test of the conditional Euler equation (3), where the attribute of book-to-market is the conditioning variable. We do not test the SDFs with the unconditional Euler equation on the excess return of small- versus large-capitalization stocks because there is no size premium in our sample period.

\section{Observation Error in the Consumption Data}

Observation error in the consumption data is a major problem both in our investigation and in related ones. In testing the Euler equations of consumption under the assumption of complete consumption insurance and limited capital market participation, we calculate per capita consumption in a quarter as the average consumption of households that are classified as asset holders, on the basis of a certain threshold of household assets holdings. The number of households in each subsample is small, and the estimated per capita consumption is noisy.

Observation error is even more problematic when we test the Euler equations of consumption under the assumption of incomplete con-

\footnotetext{
${ }^{7}$ We motivate the interpretation of the statistic $u$ as the unexplained mean premium by writing eq. (11) as

$$
0=T^{-1} \sum_{t=1}^{T} m_{\imath}\left[R_{M, t}-R_{F, t}-\left(T^{-1} \sum_{t=1}^{T} m_{t}\right)^{-1} u\right] \approx T^{-1} \sum_{t=1}^{T} m_{t}\left(R_{M, t}-R_{F, t}-u\right)
$$
}

since $\left(T^{-1} \sum_{t=1}^{T} m_{t}\right)^{-1}$ is approximately equal to $E\left[R_{F, t}\right]$, which is approximately equal to one. 
sumption insurance. The individual household's marginal rate of substitution is calculated by raising the individual household's consumption growth to a power equal to the negative of the RRA coefficient. If the reported consumption growth of even one household out of many is substantially smaller than one, this household's marginal rate of substitution is large and may dominate the weighted average of the marginal rates of substitution.

The standard remedy of trimming the sample of household consumption growth rates is a double-edged sword that we apply with caution. The potentially interesting events that help distinguish between the pricing implications of models of complete and incomplete consumption insurance are the major uninsurable shocks to a household's income, such as job loss or divorce. If these shocks are uninsurable, they result in household consumption growth in the tails of the distribution.

We illustrate the implications of a multiplicative and unbiased observation error in the consumption level, in the context of the hypothesis of complete consumption insurance. The SDF is given by equation (9). We assume that the observed per capita consumption is $c_{t} w_{t}$, where the observation error, $w_{t}$, has the following properties: $w_{t}>0 ; E\left[w_{t}\right]=1 ; w_{t}$ is identically distributed, but possibly serially correlated; and $w_{t}$ is independent of all other variables in the Euler equation. The unexplained premium statistic, $u$, in equation (11) is

$$
u=\beta T^{-1} \sum_{t=1}^{T}\left(\frac{c_{t}}{c_{t-1}}\right)^{-\alpha}\left(R_{M, t}-R_{F, t}\right) w_{t}^{-\alpha} w_{t-1}^{\alpha} .
$$

Under the null hypothesis that the Euler equation holds, the mean value of the statistic is zero. Therefore, observation error of the particular form assumed here does not bias the unexplained risk premium statistic.

We also test the Euler equation on the risk-free rate, $R_{F ;}$, as the real return on a one-month, rolled-over Treasury bill rate by testing whether the implied subjective discount factor, $\beta$, is close to but less than one. The estimated subjective discount factor is

$$
\hat{\beta}=\left[T^{-1} \sum_{t=1}^{T}\left(\frac{c_{t}}{c_{t-1}}\right)^{-\alpha} w_{t}^{-\alpha} w_{t-1}^{\alpha} R_{F, t}\right]^{-1}
$$

and is biased downward by the multiplicative factor $\left\{E\left[w_{t}^{-\alpha} w_{t-1}^{\alpha}\right]\right\}^{-1} \leq 1 .^{8}$

\footnotetext{
${ }^{8}$ This inequality follows from the fact that $w_{t}^{-\alpha} w_{t-1}^{\alpha}$ and its inverse are symmetrically distributed and

$$
\begin{aligned}
1 & =E\left[\left(w_{t}^{-\alpha} w_{t-1}^{\alpha}\right)\left(w_{t}^{-\alpha} w_{t-1}^{\alpha}\right)^{-1}\right] \leq E\left[w_{t}^{-\alpha} w_{t-1}^{\alpha}\right] E\left[\left(w_{t}^{-\alpha} w_{t-1}^{\alpha}\right)^{-1}\right] \\
& =\left\{E\left[w_{t}^{-\alpha} w_{t-1}^{\alpha}\right]\right\}^{2} .
\end{aligned}
$$
}


As predicted, the estimated subjective discount factor is severely biased downward. The bias renders the estimates meaningless, and therefore, they are not reported in the paper.

In the case of incomplete consumption insurance, similar arguments lead to the conclusion that observation error of the particular form assumed here does not bias the unexplained risk premium statistic but biases downward the estimated subjective discount factor. This bias is more severe than in the case of complete consumption insurance because the observed household consumption has substantially higher error than the observed per capita consumption.

\section{E. Small-Sample Properties of the Statistics}

The second major problem both in our investigation and in related ones is the small size of the database, both in the time series and in the number of households in the cross section. The database consists of returns and household consumption data for 60 quarters. With such a short time series, the standard error of the estimated mean equity premium is large, and we may be unable to reject the hypothesis that the mean equity premium is zero. Furthermore, we may be unable to detect the incremental contribution of relaxing the assumption of complete consumption insurance in explaining the equity premium.

Finally, the uninsurable idiosyncratic shocks to the households' income that the theory attempts to capture, such as job loss or divorce, are infrequent events relative to both the length of the time series and the number of households in the cross section.

In the empirical section, we address these problems by calculating the small-sample distribution of the $F$-statistic by the bootstrap method and adjusting the $p$-value accordingly.

\section{Description of the Data}

\section{A. The Consumption Data}

The source of the household-level quarterly consumption data is the Consumer Expenditure Survey, produced by the Bureau of Labor Statistics (BLS). ${ }^{9}$ This series of cross sections covers the period 1980:12000:4. Each quarter, roughly 5,000 U.S. households are surveyed, chosen randomly according to stratification criteria determined by the U.S. Census.

Each household participates in the survey for five consecutive quarters, one training quarter and four regular ones, during which its recent

\footnotetext{
${ }^{9}$ Among the uses of the survey is the calculation of weights on individual components of the market basket of goods used in creating the consumer price index (CPI).
} 
consumption and other information are recorded. At the end of its fifth quarter, another household, chosen randomly according to stratification criteria determined by the U.S. Census, replaces the household. The cycle of the households is staggered uniformly across the quarters such that new households replace approximately one-fifth of the participating households each quarter. ${ }^{10}$ If a household moves away from the sample address, it is dropped from the survey. The new household that moves into this address is screened for eligibility and is included in the survey. The number of households in the database varies from quarter to quarter.

The survey attempts to account for an estimated 95 percent of all quarterly household expenditures in each consumption category from a highly disaggregated list of consumption goods and services. At the end of the fourth regular quarter, data are also collected on the demographics and financial profiles of the households, including the value of asset holdings as of the month preceding the interview. We use consumption data only from the regular quarters since we consider the data from the training quarter unreliable. In a significant number of years, the BLS did not survey rural households. Therefore, we consider only urban households.

The CEX survey reports are categorized in three tranches, which we term the January, February, and March tranches. For a given year, the first-quarter consumption of the January tranche corresponds to consumption over January, February, and March; for the February tranche, first-quarter consumption corresponds to consumption over February, March, and April; for the March tranche, first-quarter consumption corresponds to consumption over March, April, and May; and so on for the second-, third-, and fourth-quarter consumption. Whereas the CEX consumption data are presented on a monthly frequency, for some consumption categories, the numbers reported as monthly are simply quarterly estimates divided by three. ${ }^{11}$ Thus utilizing monthly consumption is not an option.

Following Attanasio and Weber (1995), we discard from our sample the consumption data for the years 1980 and 1981 because they are of questionable quality. Starting in interview period 1986:1, the BLS changed its household identification numbering system without provid-

\footnotetext{
${ }^{10}$ If we were to exclude the training quarter in classifying a household as being in the panel, then each household would stay in the panel for four quarters and new households would replace one-fourth of the participating households each quarter. The constant rotation of the panel makes it impossible to test hypotheses regarding a specific household's behavior through time for more than four quarters. A longer time series of individual households' consumption is available from the PSID database, albeit only on food consumption.

${ }^{11}$ See Attanasio and Weber (1995) and Souleles (1999) for further details regarding the database.
} 
ing the correspondence between the 1985:4 and 1986:1 identification numbers of households interviewed in both quarters. This change in the identification system makes it impossible to match households across the 1985:4-1986:1 gap and results in the loss of some observations. This problem recurs between 1996:1 and 1997:1. In this instance, we opt to end our sample in 1996:1. Thus our sample covers the period 1982:11996:1.

\section{B. Definition of the Consumption Variables}

For each tranche, we calculate each household's quarterly consumption of nondurables and services by aggregating the household's quarterly consumption across the consumption categories included in the definition of nondurables and services. We employ aggregation weights that adhere to the National Income and Product Accounts (NIPA) definitions of consumption of nondurables and services. In addition, we deflate each household's consumption to the 1996:1 level, using the CPI for consumption of nondurables and services. We obtain the CPI series from the BLS through Citibase.

A household's consumption growth between quarters $t-1$ and $t$ is defined as the ratio of the household's consumption in quarters $t$ and $t-1$. The household's consumption growth is seasonally adjusted by using the additive adjustments obtained from the per capita consumption growth, as described below.

The per capita consumption of a set of households is calculated as follows. First, the consumption of each household is normalized by dividing it by the number of family members in the household. Second, the normalized household consumptions are averaged across the set of households. The per capita consumption growth between quarters $t-$ 1 and $t$ is defined as the ratio of the per capita consumption in quarters $t$ and $t-1$. For each tranche, the per capita consumption growth is seasonally adjusted by using additive adjustments obtained from regression on all the quarterly consumption growths.

\section{Household Selection Criteria}

In any given quarter, we delete from the sample households that in that quarter report as zero their total consumption, their consumption of nondurables and services, or their food consumption. In any given quarter, we also delete from the sample households with missing information on these items.

We define a household's beginning total assets as the sum of the household's market value of stocks, bonds, mutual funds, and other securities 
at the beginning of the first regular quarter. ${ }^{12}$ We define as asset holders the households that report total assets exceeding a certain threshold. We present results for threshold values ranging from $\$ 0$ to $\$ 40,000$ in 1996:1 dollars. The number of households that are included as asset holders in our sample varies across quarters and across thresholds.

We mitigate observation error by subjecting the households to a consumption growth filter. The filter consists of the following three selection criteria. First, we delete from the sample households with consumption reported in fewer than three consecutive quarters. Second, we delete the consumption growth $c_{i, t} / c_{i, t-1}$ if $c_{i, t} / c_{i, t-1}<\frac{1}{2}$ and $c_{i, t+1} / c_{i, t}>2$. Third, we delete the consumption growth $c_{i, t} / c_{i, t-1}$ if it is greater than five. The surviving subsample of households is substantially smaller than the original one.

In table 1, we present summary statistics on the quarterly per capita consumption of nondurables and services for the period 1982:11996:1, in 1996:1 dollars, for a variety of definitions of asset holders. Given that we drop quarters for which the consumption growth filter is undefined, there are 52 usable quarters in the 1982:1-1996:1 period. Per capita consumption is obtained from the CEX, with asset holders defined as the households in the database that report total assets, in 1996:1-adjusted dollars, satisfying the listed criterion and satisfying the consumption-growth filter. We present summary statistics separately for each of the three tranches, January, February, and March.

Among all the tranches, the total number of households with any amount of assets ranges between 533 and 825 . The number of households that are classified as asset holders diminishes rapidly as the threshold value is raised. Among all the tranches and across time, the number of households with assets exceeding $\$ 2,000$ ranges between 30 and 113, and the number of households with assets exceeding $\$ 20,000$ ranges between 13 and 71. A high threshold in the definition of asset holders eliminates households that are inframarginal in the capital markets but decreases the number of households in the database. We recognize this trade-off by presenting empirical results for a wide range of threshold values.

The standard deviation of the per capita consumption growth rate is large, reflecting the fact that the number of households in each subsample is small. For some subsamples, the sample mean of the per capita consumption growth is negative but well within one standard deviation from zero.

${ }^{12}$ During the fifth and last interview, the household is asked to report both the end-ofperiod asset holdings and the change in these asset holdings relative to a year earlier. From this we calculate the household's asset holdings at the beginning of the first regular quarter. 
TABLE 1

Summary Statistics on Per Capita Quarterly Consumption

\begin{tabular}{|c|c|c|c|c|c|c|c|}
\hline & \multicolumn{3}{|c|}{ Number of Households } & \multicolumn{2}{|c|}{$\begin{array}{l}\text { HOUSEHOLD CON- } \\
\text { SUMPTION LEVEL }\end{array}$} & \multicolumn{2}{|c|}{$\begin{array}{c}\text { HOUSEHOLD CON- } \\
\text { SUMPTION } \\
\text { GROWTH RATE }\end{array}$} \\
\hline & Minimum & Median & Maximum & Mean & $\begin{array}{l}\text { Standard } \\
\text { Deviation }\end{array}$ & Mean & $\begin{array}{l}\text { Standard } \\
\text { Deviation }\end{array}$ \\
\hline & \multicolumn{7}{|c|}{ A. Total Assets $\geq \$ 0$} \\
\hline January & 552 & 692 & 825 & 2,437 & 368 & -.01 & .06 \\
\hline February & 569 & 682 & 761 & 2,466 & 370 & -.01 & .07 \\
\hline \multirow[t]{2}{*}{ March } & 533 & 688 & 794 & 2,436 & 378 & -.01 & .06 \\
\hline & \multicolumn{7}{|c|}{ B. Total Assets $\geq \$ 2,000$} \\
\hline January & 31 & 80 & 108 & 3,351 & 528 & .00 & .08 \\
\hline February & 30 & 81 & 104 & 3,426 & 554 & -.01 & .09 \\
\hline \multirow[t]{2}{*}{ March } & 39 & 81 & 113 & 3,469 & 606 & .00 & .09 \\
\hline & \multicolumn{7}{|c|}{ C. Total Assets $\geq \$ 10,000$} \\
\hline January & 22 & 53 & 80 & 3,541 & 560 & .00 & .10 \\
\hline February & 18 & 54 & 76 & 3,621 & 583 & -.02 & .10 \\
\hline \multirow[t]{2}{*}{ March } & 23 & 56 & 83 & 3,665 & 631 & -.01 & .11 \\
\hline & \multicolumn{7}{|c|}{ D. Total Assets $\geq \$ 20,000$} \\
\hline January & 14 & 40 & 69 & 3,657 & 605 & .00 & .10 \\
\hline February & 13 & 40 & 63 & 3,764 & 606 & -.02 & .10 \\
\hline March & 16 & 40 & 71 & 3,773 & 681 & -.01 & .12 \\
\hline $\begin{array}{l}\text { NotE. -We } \\
\text { households fo } \\
\text { aggregating t } \\
\text { of nondurabl } \\
\text { nondurables } \\
\text { are deflated t } \\
\text { from the BLS } \\
\text { and consump } \\
\text { observations i } \\
\text { total assets, in } \\
\text { groups) label }\end{array}$ & $\begin{array}{l}\text { present summa } \\
\text { the period } 198 \\
\text { e household's } \\
\text { s and services. } \\
\text { nd services. The } \\
\text { the } 1996: 1 \text { leve } \\
\text { through Citibas } \\
\text { ion growth for } \\
\text { the particular a } \\
\text { 1996-adjusted de }\end{array}$ & $\begin{array}{l}\text { statistics or } \\
: 1-1996: 1 . \mathrm{T} \\
\text { arterly const } \\
\text { e employ ag } \\
\text { ousehold co } \\
\text { using the Cl } \\
\text { We report s } \\
\text { variety of de } \\
\text { et-holding la } \\
\text { lars. We pres }\end{array}$ & $\begin{array}{l}\text { the quarterly pe } \\
\text { household's co } \\
\text { nption across th } \\
\text { egation weights } \\
\text { sumption data a } \\
\text { for consumptio } \\
\text { mple means and } \\
\text { nitions of asset } \\
\text { r. Asset holders } \\
\text { nt summary stati }\end{array}$ & $\begin{array}{l}\text { capita co } \\
\text { umption } \\
\text { ionsumpt } \\
\text { at adhere } \\
\text { filtered u } \\
\text { of nondu } \\
\text { andard d } \\
\text { Iders as } \\
\text { defined }\end{array}$ & $\begin{array}{l}\text { umption of n } \\
\text { nondurables } \\
\text { categories th } \\
\text { the NIPA def } \\
\text { g the method } \\
\text { les and service } \\
\text { ations for bot } \\
\text { l as summary } \\
\text { the household } \\
\text { for each of th }\end{array}$ & $\begin{array}{l}\text { durables } \\
\text { l services } \\
\text { constitut } \\
\text { itions of } \\
\text { escribed } \\
\text { We obtai } \\
\text { he level } \\
\text { tistics on } \\
\text { the data }\end{array}$ & $\begin{array}{l}\text { nd services by } \\
\text { s calculated by } \\
\text { the definition } \\
\text { onsumption of } \\
\text { Sec. III } C \text { and } \\
\text { the CPI series } \\
\text { f consumption } \\
\text { he number of } \\
\text { ase that report }\end{array}$ \\
\hline
\end{tabular}

\section{The Returns Data}

Our measure of the nominal, monthly risk-free rate of interest is the one-month Treasury bill return. We calculate the three-month nominal return as the compounded buy-and-hold, three-month return. The real quarterly risk-free rate is calculated as the nominal risk-free rate, divided by the three-month (one plus) inflation rate, based on the deflator defined for nondurables and services.

The value-weighted nominal, monthly market return (capital gain plus dividends) is an arithmetic return. It is calculated from the pooled sample of stocks listed on the New York Stock Exchange and the American Stock Exchange, obtained from the Center for Research in Security Prices of the University of Chicago. We calculate the nominal, quarterly market return as the compounded buy-and-hold, three-month invest- 
ment. We calculate the real quarterly market return as the nominal market return, divided by the three-month (one plus) rate of inflation. Finally, we calculate the quarterly premium on the value-weighted portfolio as the difference between the real quarterly market return and the real quarterly interest rate. We also report results using the equally weighted market return.

We calculate the excess return of high-book-to-market versus lowbook-to-market stocks as in Fama and French (1993). The excess return is the difference of the return of the high-book-to-market and low-bookto-market portfolios.

\section{Empirical Results on the Equity Premium under Incomplete Consumption Insurance}

\section{A. The Main Results}

We begin by testing the hypothesis that the equally weighted sum of the households' marginal rates of substitution is a valid SDF. Specifically, we test the hypothesis that the SDF, given by equation (4), satisfies equation (10) on the equally weighted and on the value-weighted market premia. We set the subjective discount factor equal to one and consider values of the RRA coefficient in the range zero to nine. We calculate the unexplained premium statistic, $u$, as in equation (11) over the period 1982:1-1996:1 and test the hypothesis that the unexplained premium equals zero.

In panel A of table 2, we report the unexplained premium of the value-weighted market portfolio for each of the three tranches separately and for the combined tranches. We discuss first the results for the three tranches separately. We calculate the standard error of the unexplained premium as the sample standard deviation of the time-series observations of the quantity $m_{t}\left(R_{M, t}-R_{F, t}\right)$. We report the $p$-value of the null hypothesis $u=0$ against an unspecified alternative, based on the $t$ statistic.

In the first row, the RRA coefficient is set equal to zero, and therefore, the SDF is identically equal to one. The unexplained premium is the sample mean of the entire market premium. For the January tranche, the premium is 2.10 percent per quarter and is statistically significant with a $p$-value of 2 percent. The premium is significant for the February and March tranches also. Thus there is a premium that needs to be explained in the sample period, and this observation motivates the search for a suitable SDF.

In the second to tenth rows, we report the unexplained premium and the $p$-value of the null hypothesis $u=0$. For each of the tranches, the unexplained premium becomes statistically insignificant when the RRA 
TABLE 2

Unexplained Equity Premium under Incomplete Consumption Insurance

\begin{tabular}{|c|c|c|c|c|c|c|c|c|c|}
\hline \multirow[b]{2}{*}{ RRA } & \multicolumn{3}{|c|}{ Combined Tranches } & \multicolumn{2}{|c|}{ JANUARY TRANChE } & \multicolumn{2}{|c|}{ February Tranche } & \multicolumn{2}{|c|}{ March Tranche } \\
\hline & $\begin{array}{c}\text { Average } \\
\text { Unexplained } \\
\text { Premium }\end{array}$ & $\begin{array}{c}F \text {-Statistic } \\
p \text {-Value }\end{array}$ & $\begin{array}{c}F \text {-Statistic } \\
\text { Bootstrap } \\
p \text {-Value }\end{array}$ & $\begin{array}{c}\text { Average } \\
\text { Unexplained } \\
\text { Premium }\end{array}$ & $\begin{array}{c}{ }^{t} \text {-Statistic } \\
p \text {-Value }\end{array}$ & $\begin{array}{c}\text { Average } \\
\text { Unexplained } \\
\text { Premium }\end{array}$ & $\begin{array}{c}t \text {-Statistic } \\
p \text {-Value }\end{array}$ & $\begin{array}{c}\text { Average } \\
\text { Unexplained } \\
\text { Premium }\end{array}$ & $\begin{array}{c}t \text {-Statistic } \\
p \text {-Value }\end{array}$ \\
\hline & \multicolumn{9}{|c|}{ A. Value-Weighted Equity Premium } \\
\hline 0 & 1.85 & .04 & .06 & 2.10 & .02 & 2.07 & .02 & 2.46 & .01 \\
\hline 1 & 1.95 & .04 & .06 & 2.33 & .01 & 2.12 & .02 & 2.56 & .02 \\
\hline 2 & 2.32 & .06 & .07 & 3.02 & .01 & 2.42 & .05 & 2.99 & .02 \\
\hline 3 & 1.88 & .74 & .69 & 3.85 & .11 & 2.36 & .20 & 1.50 & .31 \\
\hline 4 & $<-10$ & .52 & .59 & $<-10$ & .60 & $<-10$ & .74 & $<-10$ & .84 \\
\hline 5 & $<-10$ & .28 & .52 & $<-10$ & .67 & $<-10$ & .91 & $<-10$ & .88 \\
\hline 6 & $<-10$ & .24 & .54 & $<-10$ & .64 & $<-10$ & .95 & $<-10$ & .91 \\
\hline 7 & $<-10$ & .23 & .53 & $<-10$ & .65 & $<-10$ & .94 & $<-10$ & .89 \\
\hline 8 & $<-10$ & .24 & .58 & $<-10$ & .69 & $<-10$ & .94 & $<-10$ & .89 \\
\hline \multirow[t]{2}{*}{9} & $<-10$ & .26 & .63 & $<-10$ & .69 & $<-10$ & .94 & $<-10$ & .90 \\
\hline & \multicolumn{9}{|c|}{ B. Equally Weighted Equity Premium } \\
\hline 0 & 1.78 & .21 & .22 & 2.09 & .06 & 1.98 & .07 & 2.27 & .04 \\
\hline 1 & 1.83 & .24 & .24 & 2.38 & .04 & 1.95 & .08 & 2.28 & .06 \\
\hline 2 & 2.00 & .36 & .29 & 3.05 & .04 & 2.04 & .12 & 2.31 & .10 \\
\hline 3 & -.20 & .86 & .81 & 2.53 & .28 & .77 & .39 & -4.63 & .74 \\
\hline 4 & $<-10$ & .31 & .57 & $<-10$ & .70 & $<-10$ & .88 & $<-10$ & .95 \\
\hline 5 & $<-10$ & .20 & .56 & $<-10$ & .76 & $<-10$ & .96 & $<-10$ & .99 \\
\hline 6 & $<-10$ & .18 & .55 & $<-10$ & .83 & $<-10$ & .95 & $<-10$ & .99 \\
\hline 7 & $<-10$ & .17 & .59 & $<-10$ & .84 & $<-10$ & .97 & $<-10$ & 1.00 \\
\hline 8 & $<-10$ & .19 & .57 & $<-10$ & .86 & $<-10$ & .97 & $<-10$ & 1.00 \\
\hline 9 & $<-10$ & .21 & .59 & $<-10$ & .87 & $<-10$ & .97 & $<-10$ & 1.00 \\
\hline
\end{tabular}

NoTE. - We calculate the unexplained premium statistic, $u$, on the basis of the SDF in eq. (4) over the period 1982:1-1996:1 and test the hypothesis that the unexplained premium equals zero. $p$-values of the null hypothesis $u=0$ against an unspecified alternative are based on either asymptotic normality or bootstrapped distribution (see Sec. IVA). 
coefficient becomes three and crosses zero between the values of three and four. The sign of the unexplained premium becomes negative for an RRA coefficient of four or higher. Therefore, we do not reject the hypothesis that the equally weighted sum of the households' marginal rate of substitution is a valid SDF with RRA coefficient equal to three. An RRA coefficient of this order of magnitude is economically plausible.

A standard generalized method of moments (GMM) estimate of risk aversion in the exactly identified case can be inferred from table 2 and others that report unexplained premia for various levels of risk aversion. In an exactly identified GMM risk aversion estimation, the weighting matrix essentially plays no role. The sole determinant of the risk aversion estimate then is pricing error, the squared function of which GMM minimizes. This same estimate can be read off of our unexplained premium tables with a negligible amount of eyeball interpolation. For instance, the value-weighted premium unexplained under complete consumption insurance in panel A of table 2 crosses a value of zero (for the combined tranches) for an RRA between three and four. For the equally weighted case, the unexplained premium crosses zero between values of two and three for the RRA, although probably closer to three than two.

Note that each household in the sample is represented in only one of the three tranches. If a household's consumption growth is an outlier, this outlier cannot influence the results in more than one of the tranches. The fact that the estimated unexplained premia and the $p$ values are very similar for the three tranches is evidence that the results are robust to observation error on the households' consumption growth.

We also report the unexplained premium for the combined tranches. The unexplained premium is calculated as the weighted average of the unexplained premia of the three tranches, where the weights are determined from the weighted least squares quadratic form $\left(\mathbf{1}_{3}{ }^{\prime} \mathbf{V}^{-1} \mathbf{1}_{3}\right)^{-1} \mathbf{1}_{3}{ }^{\prime} \mathbf{u}_{3}$, where $\mathbf{u}_{3}$ is a $3 \times 1$ vector of estimated unexplained premia for the three tranches, $\mathbf{V}$ is the diagonal of the $3 \times 3$ covariance matrix, and $\mathbf{1}_{3}$ is a $3 \times 1$ unit vector. ${ }^{13}$ We thus weight each mean by a measure of its volatility. Unweighted arithmetic means produce qualitatively similar results, as means calculated using the entire covariance matrix (generalized least squares) do. We calculate the $F$-statistic and

\footnotetext{
${ }^{13}$ We note that as a result of the identification problem that hampers the ability to match households between 1985:4 and 1986:1, individual tranches have different timeseries lengths. This difference affects the calculation of the combined average unexplained premia and the $F$-statistic and bootstrap $p$-values reported. These quantities are calculated for the combined cases using the time frame common for all tranches. This explains why, in some cases, the combined premia fall outside the range of the individual tranche estimates. An alternative would be to truncate ex ante the time series for all tranches to a common time frame. We eschew this approach, however, since it discards information unnecessarily.
} 
report the $p$-value of the null hypothesis that the combined unexplained premium is zero. We also calculate the small-sample distribution of the $F$-statistic by the bootstrap method and report the $p$-value. Specifically, the $F$-statistic is the Hotelling $T^{2}$ test of the null that the mean unexplained premia are jointly zero: $[T(T-3) / 3(T-1)]\left(\mathbf{u}_{3}{ }^{\prime} \mathbf{V}^{-1} \mathbf{u}_{3}\right)^{-1} \sim$ $F_{3, T-3}$. We utilize a block bootstrap with a block size of four quarters.

In the first row of panel A of table 2, the sample mean of the entire premium for the combined tranches is 1.85 percent per quarter and is marginally significant. In the second to tenth rows, we report the unexplained premium and the $p$-value of the null hypothesis $u=0$ for increasing values of the RRA coefficient. The unexplained premium becomes statistically insignificant when the RRA coefficient becomes three, and the sign of the unexplained premium becomes negative for an RRA coefficient of four or higher, consistent with the results for the individual tranches.

In panel B of table 2, we report the unexplained premium of the equally weighted market portfolio for each of the three tranches separately and for the combined tranches. The sample mean of the entire premium for the combined tranches is 1.78 percent per quarter, but with a $p$-value of about 20 percent, it is not significant. For the individual tranches, the premium is significant at the 10 percent level. For the three tranches separately and for the combined tranches, the unexplained premium reverses sign when the RRA coefficient is either three or four. Overall, the pattern of the unexplained premia of the equally weighted market portfolio is consistent with the earlier results on the value-weighted market portfolio. This suggests that the results are robust to outliers in the portfolio returns and to the composition of the market portfolio.

\section{B. Robustness of the Results}

We explore further the robustness of the empirical results presented in table 2. We expand the SDF as a Taylor series up to cubic terms, as in equation (5), and test the hypothesis that the expanded SDF satisfies equation (10) on the value-weighted and on the equally weighted market premia. The SDF is expressed in terms of the cross-sectional mean, variance, and skewness of the household consumption growth rate. The motivation for this procedure is that the estimation of the cross-sectional moments may be less susceptible to outliers than the estimation of the SDF in equation (4): the estimates of the cross-sectional moments are independent of the RRA coefficient, whereas the SDF in equation (4) is very sensitive to outliers in the household consumption growth when the RRA coefficient is large.

The results are reported in table 3 and are similar to the results 
TABLE 3

ARithmetic Expansion of THE SDF UNDER InCOMPlete CONSUmption INSURANCE

\begin{tabular}{|c|c|c|c|c|c|c|c|c|c|}
\hline \multirow[b]{2}{*}{ RRA } & \multicolumn{3}{|c|}{ 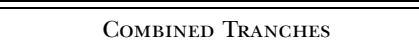 } & \multicolumn{2}{|c|}{ January Tranche } & \multicolumn{2}{|c|}{ February Tranche } & \multicolumn{2}{|c|}{ March Tranche } \\
\hline & $\begin{array}{l}\text { Average } \\
\text { Unexplained } \\
\text { Premium }\end{array}$ & $\begin{array}{c}F \text { Statistic } \\
p \text {-Value }\end{array}$ & $\begin{array}{c}F \text {-Statistic } \\
\text { Bootstrap } \\
p \text {-Value }\end{array}$ & $\begin{array}{l}\text { Average } \\
\text { Unexplained } \\
\text { Premium }\end{array}$ & $\begin{array}{c}t \text {-Statistic } \\
p \text {-Value }\end{array}$ & $\begin{array}{l}\text { Average } \\
\text { Unexplained } \\
\text { Premium }\end{array}$ & $\begin{array}{c}t \text {-Statistic } \\
p \text {-Value }\end{array}$ & $\begin{array}{c}\text { Average } \\
\text { Unexplained } \\
\text { Premium }\end{array}$ & $\begin{array}{c}t \text {-Statistic } \\
p \text {-Value }\end{array}$ \\
\hline & \multicolumn{9}{|c|}{ A. Value-Weighted Equity Premium } \\
\hline 0 & 1.85 & .04 & .05 & 2.10 & .02 & 2.07 & .02 & 2.46 & .01 \\
\hline 1 & 1.76 & .03 & .05 & 2.07 & .01 & 1.91 & .02 & 2.32 & .01 \\
\hline 2 & 1.51 & .02 & .03 & 1.80 & .01 & 1.56 & .04 & 1.98 & .01 \\
\hline 3 & .90 & .05 & .03 & 1.05 & .01 & .86 & .07 & 1.21 & .01 \\
\hline 4 & -.22 & .96 & .97 & -.40 & .77 & -.30 & .68 & -.15 & .57 \\
\hline 5 & -1.85 & .44 & .43 & -2.74 & .96 & -1.99 & .89 & -2.26 & .79 \\
\hline 6 & -4.12 & .32 & .26 & -6.16 & .98 & -4.27 & .90 & -5.23 & .83 \\
\hline 7 & -7.12 & .27 & .27 & $<-10$ & .98 & -7.16 & .90 & -9.22 & .83 \\
\hline 8 & $<-10$ & .26 & .21 & $<-10$ & .99 & $<-10$ & .89 & $<-10$ & .84 \\
\hline \multirow[t]{2}{*}{9} & $<-10$ & .25 & .24 & $<-10$ & .99 & $<-10$ & .88 & $<-10$ & .87 \\
\hline & \multicolumn{9}{|c|}{ B. Equally Weighted Equity Premium } \\
\hline 0 & 1.78 & .21 & .20 & 2.09 & .06 & 1.98 & .07 & 2.27 & .04 \\
\hline 1 & 1.68 & .21 & .21 & 2.11 & .04 & 1.80 & .08 & 2.12 & .05 \\
\hline 2 & 1.46 & .15 & .17 & 1.84 & .04 & 1.50 & .08 & 1.84 & .02 \\
\hline 3 & .97 & .12 & .07 & 1.02 & .06 & .98 & .08 & 1.32 & .02 \\
\hline 4 & -.15 & .87 & .90 & -.64 & .81 & .17 & .44 & .48 & .40 \\
\hline 5 & -1.59 & .65 & .57 & -3.38 & .94 & -.96 & .67 & -.73 & .61 \\
\hline 6 & -3.61 & .56 & .53 & -7.46 & .97 & -2.44 & .71 & -2.31 & .67 \\
\hline 7 & -6.29 & .51 & .45 & $<-10$ & .98 & -4.29 & .73 & -4.29 & .69 \\
\hline 8 & $<-10$ & .48 & .40 & $<-10$ & .98 & -6.53 & .71 & -6.67 & .68 \\
\hline 9 & $<-10$ & .46 & .39 & $<-10$ & .98 & -9.22 & .68 & -9.47 & .68 \\
\hline
\end{tabular}

NotE. - We calculate the unexplained premium statistic, $u$, on the basis of the SDF in eq. (5) over the period 1982:1-1996:1 and test the hypothesis that the unexplained premium equals zero. The SDF employed here is expressed in terms of the cross-sectional mean, variance, and skewness of the household consumption growth rate. See 
presented in table 2. For each of the three tranches separately and for the combined tranches, the unexplained, value-weighted equity premium is negative for an RRA coefficient of four or higher. We obtain similar results for the equally weighted equity premium. For the January tranche and for the combined tranches, the sign change occurs for an RRA coefficient equal to four; for the January and February tranches, the sign change occurs for an RRA coefficient equal to five.

For a high-RRA coefficient, the unexplained premium in table 3 is negative but not as negative as in table 2 . This is consistent with the explanation that the estimation of the cross-sectional moments is less susceptible to outliers than the estimation of the SDF in equation (4).

The finding that the SDF as in equation (5) explains the equity premium with only a slightly higher RRA coefficient than the SDF as in equation (4) suggests that the cross-sectional variance and skewness of the household consumption growth rate capture most of the cross-sectional variation of the households' consumption growth rates.

\section{The Role of the Cross-Sectional Skewness of the Consumption Growth Rate}

We investigate the role of the cross-sectional skewness of the household consumption growth rate in explaining the equity premium by expanding the SDF as a Taylor series up to quadratic terms, as in equation (6), and testing the hypothesis that the expanded SDF satisfies equation (10) on the value-weighted and on the equally weighted market premia. The SDF is expressed in terms of the cross-sectional mean and variance, but not skewness, of the household consumption growth rate. Thus the SDF differs from the SDF of equation (5) only in that the skewness of the cross-sectional consumption growth rate is suppressed.

The results are reported in columns 1-3 of table 4, panels A and B. The unexplained value-weighted equity premium not only remains positive for all values of the RRA coefficient between zero and nine but also increases as the RRA coefficient increases. However, the unexplained premium is insignificant at the 5 percent level for an RRA coefficient of two or higher, with $p$-values ranging to 10 percent for an RRA coefficient equal to nine. The unexplained equally weighted equity premium also remains positive and increasing for all values of the RRA coefficient between zero and nine but is not statistically significant. These results underscore the importance of the skewness of the household consumption growth rate, combined with the first two moments of the cross-sectional distribution, in explaining the equity premium.

We explore further the importance of the skewness by testing a variant of the expansion of the SDF, given by equation (5). We define $G_{i, t}=$ $\log \left(c_{i, t}\right)-\log \left(c_{i, t-1}\right)$ as the logarithmic consumption growth of the $i$ th 
TABLE 4

Additional Tests under Incomplete Consumption Insurance

\begin{tabular}{|c|c|c|c|c|c|c|c|c|c|c|c|c|}
\hline \multirow[b]{2}{*}{ RRA } & \multicolumn{3}{|c|}{ SDF: EQ. (6) } & \multicolumn{3}{|c|}{ SDF: EQ. (7) } & \multicolumn{3}{|c|}{ SDF: EQ. (8) } & \multicolumn{3}{|c|}{ SDF: EQ. (9) } \\
\hline & $\begin{array}{c}\text { Average } \\
\text { Unexplained } \\
\text { Premium } \\
\text { (1) }\end{array}$ & $\begin{array}{c}F \text {-Statistic } \\
p \text {-Value } \\
(2)\end{array}$ & $\begin{array}{c}F \text {-Statistic } \\
\text { Bootstrap } \\
p \text {-Value } \\
(3)\end{array}$ & $\begin{array}{c}\text { Average } \\
\text { Unexplained } \\
\text { Premium } \\
(4)\end{array}$ & $\begin{array}{c}F \text {-Statistic } \\
p \text {-Value } \\
(5)\end{array}$ & $\begin{array}{c}F \text {-Statistic } \\
\text { Bootstrap } \\
p \text {-Value } \\
(6)\end{array}$ & $\begin{array}{c}\text { Average } \\
\text { Unexplained } \\
\text { Premium } \\
(7)\end{array}$ & $\begin{array}{c}F \text {-Statistic } \\
p \text {-Value } \\
(8)\end{array}$ & $\begin{array}{c}F \text {-Statistic } \\
\text { Bootstrap } \\
p \text {-Value } \\
(9)\end{array}$ & $\begin{array}{l}\text { Average } \\
\text { Unexplained } \\
\text { Premium } \\
(10)\end{array}$ & $\begin{array}{c}F \text {-Statistic } \\
p \text {-Value } \\
\quad(11)\end{array}$ & $\begin{array}{c}F \text {-Statistic } \\
\text { Bootstrap } \\
p \text {-Value } \\
(12)\end{array}$ \\
\hline & \multicolumn{12}{|c|}{ A. Value-Weighted Equity Premium } \\
\hline 0 & 1.85 & .04 & .05 & 1.85 & .04 & .05 & 1.85 & .04 & .05 & 1.85 & .05 & .019. \\
\hline 1 & 1.97 & .04 & .04 & 1.94 & .04 & .06 & 1.73 & .04 & .04 & 1.85 & .04 & .019. \\
\hline 2 & 2.32 & .05 & .07 & 2.30 & .05 & .06 & 1.62 & .04 & .06 & 1.87 & .05 & .019 \\
\hline 3 & 2.84 & .06 & .09 & 3.09 & .07 & .08 & 1.53 & .04 & .07 & 1.90 & .07 & 019 \\
\hline 4 & 3.53 & .07 & .09 & 4.70 & .10 & .10 & 1.46 & .04 & .04 & 1.93 & .04 & 019 \\
\hline 5 & 4.35 & .07 & .08 & 8.08 & .16 & .15 & 1.39 & .04 & .04 & 1.98 & .05 & .020 \\
\hline 6 & 5.30 & .08 & .10 & $>10$ & .22 & .22 & 1.33 & .04 & .06 & 2.04 & .06 & .020 \\
\hline 7 & 6.37 & .08 & .10 & $>10$ & .30 & .29 & 1.28 & .04 & .06 & 2.11 & .06 & .021 \\
\hline 8 & 7.54 & .08 & .09 & $>10$ & .36 & .39 & 1.23 & .04 & .07 & 2.19 & .06 & .022 \\
\hline \multirow[t]{2}{*}{9} & 8.81 & .08 & .10 & $>10$ & .39 & .46 & 1.20 & .04 & .06 & 2.28 & .06 & .023. \\
\hline & \multicolumn{12}{|c|}{ B. Equally Weighted Equity Premium } \\
\hline 0 & 1.78 & .21 & .22 & 1.78 & .21 & .23 & 1.78 & .21 & .20 & 1.78 & .21 & .20 \\
\hline 1 & 1.87 & .24 & .23 & 1.83 & .24 & .25 & 1.65 & .22 & .22 & 1.77 & .22 & .24 \\
\hline 2 & 2.15 & .27 & .25 & 2.11 & .29 & .23 & 1.54 & .22 & .22 & 1.78 & .22 & .22 \\
\hline 3 & 2.60 & .30 & .27 & 2.69 & .35 & .29 & 1.45 & .22 & .21 & 1.80 & .22 & .21 \\
\hline 4 & 3.19 & .31 & .30 & 3.81 & .44 & .33 & 1.38 & .21 & .19 & 1.83 & .22 & .22 \\
\hline 5 & 3.90 & .32 & .28 & 5.94 & .51 & .40 & 1.31 & .21 & .20 & 1.87 & .21 & .20 \\
\hline 6 & 4.73 & .32 & .28 & $>10$ & .55 & .43 & 1.26 & .20 & .17 & 1.92 & .21 & .21 \\
\hline 7 & 5.67 & .31 & .24 & $>10$ & .54 & .47 & 1.21 & .20 & .18 & 1.98 & .20 & .21 \\
\hline 8 & 6.71 & .30 & .28 & $>10$ & .49 & .48 & 1.17 & .19 & .17 & 2.05 & .19. & .17 \\
\hline 9 & 7.85 & .29 & .25 & $>10$ & .42 & .44 & 1.13 & . 18 & .15 & 2.12 & .19. & .17. \\
\hline
\end{tabular}


household. We expand equation (4) as a Taylor series up to cubic terms. We obtain the following approximation for the SDF,

$$
m_{t}=\beta e^{-\alpha G_{i}}\left[1+\frac{1}{2} \alpha^{2} I^{-1} \sum_{i=1}^{I}\left(G_{i, t}-G_{t}\right)^{2}-\frac{1}{6} \alpha^{3} I^{-1} \sum_{i=1}^{I}\left(G_{i, t}-G_{t}\right)^{3}\right],
$$

in terms of the cross-sectional mean, $G_{t}=I^{-1} \sum_{i=1}^{I} G_{i, t}$, variance, $I^{-1} \sum_{i=1}^{I}\left(G_{i, t}-G_{t}\right)^{2}$, and skewness, $I^{-1} \sum_{i=1}^{I}\left(G_{i, t}-G_{t}\right)^{2}$, of the logarithmic consumption growth rate. In empirical results that we do not display here, we find that the SDF given by equation (14) fails to explain the equity premium. These results contrast with the results reported in Section IV $B$ that the SDF given by equation (5) explains the equity premium. We surmise that, in expanding the SDF in terms of the logarithmic consumption growth rate, we suppress the effect of outliers and, in particular, suppress the effect of the skewness on the SDF. ${ }^{14}$ These results underscore further the importance of the skewness on the SDF.

\section{The Role of the Lognormality Assumption of the Household Consumption Growth Rate}

We investigate whether multiplicative and i.i.d. lognormal idiosyncratic income shocks capture the cross-sectional variation of the consumption growth rate. Under this assumption, the SDF is given by equation (7). We test the hypothesis that this SDF satisfies equation (10) on the valueweighted and on the equally weighted market premia.

The results are reported in columns 4-6 of table 4, panels A and B. The unexplained value-weighted equity premium remains positive for all values of the RRA coefficient between zero and nine and increases as the RRA coefficient increases. However, the unexplained premium is marginally insignificant at the 5 percent level for an RRA coefficient of one or higher. The unexplained equally weighted equity premium also remains positive for all values of the RRA coefficient between zero and nine but is not statistically significant. Contrasted with the results on the SDF given by equations (4) and (5), these results again underscore the importance of the skewness of the household consumption growth rate, combined with the first two moments of the cross-sectional distribution, in explaining the equity premium.

\footnotetext{
${ }^{14}$ We explore this assertion by calculating the simple correlation between the crosssectional mean, variance, and skewness based on $g_{i}$, the simple consumption growth of the $i$ th household, and $G_{i}$, the logarithm of the consumption growth of the $i$ th household. For both the cross-sectional mean and variance, we find correlations that, in general, exceed 90 percent between the two possible ways of computing these sample moments. However, the time-series sample estimates of skewness have a much lower correlation (31 percent, 49 percent, and 18 percent for the January, February, and March tranches, respectively).
} 


\section{Empirical Results on the Equity Premium under Complete Consumption Insurance}

\section{A. Tests of Complete Consumption Insurance}

If a complete set of markets exists that enables households to insure against idiosyncratic income shocks, then the heterogeneous households are able to equalize, state by state, their marginal rates of substitution. Then the SDF may be expressed in terms of the cross-sectional mean, but not skewness and variance, of the household consumption growth rate, as in equation (8). It may also be expressed in terms of the per capita growth rate, as in equation (9). We test the hypothesis of complete consumption insurance by testing whether these two SDFs satisfy equation (10) on the value-weighted and on the equally weighted market premia.

The results are reported in columns 7-12 of table 4, panels A and B. The unexplained value-weighted equity premium remains positive and statistically significant for all values of the RRA coefficient between zero and nine. This particular SDF fails to explain the equity premium.

\section{B. Tests of Complete Consumption Insurance with Limited Stock Market Participation}

We recognize the fact that only a subset of households is marginal in the stock market by defining as asset holders the subset of households that report total assets exceeding a certain threshold value ranging from $\$ 0$ to $\$ 40,000$. From the subset of households defined as asset holders, we express the SDF in terms of the per capita growth rate, as in equation (9), and repeat the tests of complete consumption insurance.

For threshold values $\$ 0, \$ 2,000, \$ 10,000, \$ 20,000, \$ 30,000$, and $\$ 40,000$, the unexplained quarterly value-weighted equity premium remains positive and statistically significant for all values of the RRA coefficient between zero and 20. These results, not reported here, suggest that the assumption of complete consumption insurance that suppresses the cross-sectional variation of the households' consumption growth rate fails to explain the quarterly equity premium even after we take into account the limited stock market participation.

We repeat the tests but now switch the holding period from three to six months. The results are reported in table 5. For threshold value $\$ 0$, the unexplained six-month value-weighted equity premium is 5.18 percent and is statistically significant at all levels of the RRA coefficient. For threshold value $\$ 2,000$, the unexplained premium drops to 3.37 percent and becomes statistically insignificant when the RRA coefficient equals 10 . For threshold value $\$ 10,000$, the unexplained premium drops to 3.07 percent and becomes statistically insignificant when the RRA 
TABLE 5

Unexplained Equity Premium under Complete Consumption Insurance and Limited Participation

\begin{tabular}{|c|c|c|c|}
\hline RRA & $u$ Statistic & $\begin{array}{c}F \text {-Statistic } \\
p \text {-Value }\end{array}$ & $\begin{array}{c}F \text {-Statistic } \\
\text { Bootstrap } p \text {-Value }\end{array}$ \\
\hline & \multicolumn{3}{|c|}{ A. Threshold Value $\geq \$ 0$} \\
\hline 0 & 5.18 & .00 & .00 \\
\hline 1 & 5.21 & .00 & .00 \\
\hline 5 & 5.29 & .00 & .07 \\
\hline 10 & 5.00 & .01 & .30 \\
\hline 15 & 4.86 & .02 & .31 \\
\hline \multirow[t]{2}{*}{20} & 4.83 & .04 & .37 \\
\hline & \multicolumn{3}{|c|}{ B. Threshold Value $\geq \$ 2,000$} \\
\hline 0 & 5.18 & .00 & .00 \\
\hline 1 & 4.91 & .00 & .00 \\
\hline 5 & 4.08 & .02 & .02 \\
\hline 10 & 3.37 & .20 & .34 \\
\hline 15 & 2.84 & .57 & .64 \\
\hline 20 & 2.50 & .79 & .83 \\
\hline
\end{tabular}

C. Threshold Value $\geq \$ 10,000$

\begin{tabular}{rcc}
\hline 5.18 & .00 & .00 \\
4.89 & .00 & .00 \\
3.97 & .03 & .03 \\
3.07 & .31 & .47 \\
2.09 & .81 & .83 \\
.51 & .94 & .93 \\
\hline \multicolumn{3}{c}{} \\
\hline 5.18 & D. Threshold Value $\geq \$ 20,000$ \\
4.82 & .05 & .03 \\
3.65 & .00 & .00 \\
2.02 & .06 & .05 \\
-.74 & .77 & .80 \\
-5.80 & .98 & .97 \\
\hline \multicolumn{3}{|c}{} \\
\hline 5.18 & .80 & .85 \\
4.82 & .00 & .00 \\
4.00 & .00 & .00 \\
3.48 & .09 & .57 \\
2.31 & .50 & .78 \\
-2.43 & .70 & .74 \\
\hline
\end{tabular}

F. Threshold Value $\geq \$ 40,000$

\begin{tabular}{|c|c|c|c|}
\hline 0 & 5.18 & .00 & .00 \\
\hline 1 & 4.71 & .00 & .00 \\
\hline 5 & 3.21 & .18 & .15 \\
\hline 10 & 1.49 & .82 & .83 \\
\hline 15 & -.38 & .92 & .90 \\
\hline 20 & -3.87 & .88 & .87 \\
\hline
\end{tabular}


coefficient equals 10 . For threshold values $\$ 20,000$ and $\$ 40,000$, the unexplained premium flips sign for RRA coefficients between 10 and 15 ; for threshold value $\$ 30,000$, the unexplained premium flips sign for RRA coefficients between 15 and 20. We interpret these results as evidence of complete consumption insurance when limited market participation is taken into account, if one considers these values of the RRA coefficient economically plausible. We repeat the tests but shift the start of the six-month holding period by one quarter. In results not reported here, we find that we are unable to explain the equity premium for any threshold value between $\$ 0$ and $\$ 40,000$ and for any RRA coefficient between zero and 20 . We conclude that, while we uncover prima facie evidence in favor of complete consumption insurance with limited participation, the results are sensitive to the empirical design.

In table 6, we report the correlation of the per capita consumption growth with the equity premium on the value-weighted and the equally weighted market indices at the six-month frequency. For each threshold value, we report the correlation for each of the January, February, and March tranches separately since there is no obvious way to combine these correlation estimates across tranches. Whereas the correlation estimates differ widely across the tranches, there is a pattern of increasing correlation as the definition of asset holders is tightened. We stress that we make no claim of statistical significance in this pattern since we do not report $p$-values in table 6 . We make statements backed with statistical significance in the context of the unexplained premium statistic. Nevertheless, these results are in line with earlier results reported by Mankiw and Zeldes (1991) and Brav and Geczy (1995) and recent results by Attanasio et al. (2002; this issue) and Vissing-Jørgensen (2002; this issue).

In summary, we find some evidence that the SDF driven by the per capita consumption growth can explain the equity premium with a relatively high value of the RRA coefficient, once we recognize the fact that only a subset of households is marginal in the stock market.

\section{Explaining the Premium of Value Stocks over Growth Stocks}

All the tests reported so far pertain to the equity premium. In this section, we report results of tests with the unconditional Euler equation on the excess return of high-book-to-market value stocks over low-bookto-market growth stocks, $R_{H, t}-R_{L, t}$ as $E\left[m_{t}\left(R_{H, t}-R_{L, t}\right)\right]=0$ and calculate the corresponding unexplained-premium statistic as $u=$ $T^{-1} \sum_{t=1} m_{t}\left(R_{H, t}-R_{L, t}\right)$. This may be viewed as a test of the conditional Euler equation (3), where the attribute of book-to-market is the conditioning variable. We do not attempt to explain the premium of smallversus large-capitalization stocks because there is no size premium in our sample period. 
TABLE 6

Calibration Results under Complete Consumption Insurance and Limited Participation

\begin{tabular}{|c|c|c|c|}
\hline & $\begin{array}{l}\text { January } \\
\text { Tranche }\end{array}$ & $\begin{array}{c}\text { February } \\
\text { Tranche }\end{array}$ & $\begin{array}{c}\text { March } \\
\text { Tranche }\end{array}$ \\
\hline & \multicolumn{3}{|c|}{ A. Total Assets $\geq \$ 0$} \\
\hline Correlation with value-weighted market & .07 & .22 & -.15 \\
\hline Correlation with equally weighted market & .07 & .19 & -.21 \\
\hline \multicolumn{4}{|l|}{ RRA: } \\
\hline Value-weighted market & 269 & 98 & -35 \\
\hline \multirow[t]{2}{*}{ Equally weighted market } & 184 & 73 & -18 \\
\hline & \multicolumn{3}{|c|}{ B. Total Assets $\geq \$ 2,000$} \\
\hline Correlation with value-weighted market & .22 & .54 & .32 \\
\hline Correlation with equally weighted market & .09 & .52 & .25 \\
\hline \multicolumn{4}{|l|}{ RRA: } \\
\hline Value-weighted market & 28 & 14 & 28 \\
\hline \multirow[t]{2}{*}{ Equally weighted market } & 53 & 9 & 26 \\
\hline & \multicolumn{3}{|c|}{ C. Total Assets $\geq \$ 10,000$} \\
\hline Correlation with value-weighted market & .21 & .47 & .25 \\
\hline Correlation with equally weighted market & .12 & .45 & .20 \\
\hline \multicolumn{4}{|l|}{ RRA: } \\
\hline Value-weighted market & 26 & 13 & 25 \\
\hline \multirow[t]{2}{*}{ Equally weighted market } & 35 & 9 & 22 \\
\hline & \multicolumn{3}{|c|}{ D. Total Assets $\geq \$ 20,000$} \\
\hline Correlation with value-weighted market & .38 & .52 & 18 \\
\hline Correlation with equally weighted market & .23 & .48 & 11 \\
\hline \multicolumn{4}{|l|}{ RRA: } \\
\hline Value-weighted market & 14 & 10 & 18 \\
\hline \multirow[t]{2}{*}{ Equally weighted market } & 17 & 7 & 34 \\
\hline & \multicolumn{3}{|c|}{ E. Total Assets $\geq \$ 30,000$} \\
\hline Correlation with value-weighted market & .26 & .52 & .08 \\
\hline Correlation with equally weighted market & .10 & .47 & .04 \\
\hline \multicolumn{4}{|l|}{ RRA: } \\
\hline Value-weighted market & 16 & 8 & 51 \\
\hline \multirow[t]{2}{*}{ Equally weighted market } & 30 & 6 & 79 \\
\hline & \multicolumn{3}{|c|}{ F. Total Assets $\geq \$ 40,000$} \\
\hline Correlation with value-weighted market & .44 & .55 & .16 \\
\hline Correlation with equally weighted market & .31 & .48 & .09 \\
\hline \multicolumn{4}{|l|}{ RRA: } \\
\hline Value-weighted market & 9 & 7 & 23 \\
\hline Equally weighted market & 9 & 5 & 30 \\
\hline
\end{tabular}


The results are reported in table 7 for the combined tranches. In the first row, the RRA coefficient is set equal to zero, and therefore, the SDF is identically equal to one. The unexplained premium is the sample mean of the entire value premium. The unexplained value premium is 1.19 percent and is significant at the 10 percent level.

In the second to tenth rows, we report the unexplained premium and the $p$-value of the null hypothesis $u=0$ under different assumptions on the SDF. In columns 1-3, we report the unexplained value premium when the SDF is given by equation (4), under the assumption of incomplete consumption insurance. The sign of the unexplained premium is reversed when the RRA coefficient lies between three and four. In columns 4-6, we report the unexplained value premium when the SDF is expressed in terms of the cross-sectional mean, variance, and skewness of the household consumption growth, as given by equation (5). The sign of the unexplained premium is reversed when the RRA coefficient lies between four and five.

By contrast, in columns 7-9, we report the unexplained value premium when the SDF is expressed in terms of the per capita consumption growth, as implied by the hypothesis of complete consumption insurance and as given by equation (9). The unexplained premium is positive, although marginally insignificant, and increases as the value of the RRA coefficient increases. We conclude that the SDF implied by a model of incomplete consumption insurance is consistent with the value premium, whereas the SDF implied by a model of complete consumption insurance is not. The results reinforce our earlier findings on the equity premium.

\section{Extensions and Concluding Remarks}

In this paper, we presented evidence that the equity premium and the premium of value stocks over growth stocks are explained with an SDF calculated as the weighted average of the individual households' marginal rate of substitution with low and economically plausible values of the RRA coefficient. Since the premia above are not explained with an SDF calculated as the per capita marginal rate of substitution with low values of the RRA coefficient, the evidence supports the hypothesis of incomplete consumption insurance. The results are robust across the value-weighted equity premium, the equally weighted equity premium, and the value-over-growth premium. The results are robust across the three distinct cohorts of households that we refer to as the January, February, and March tranches.

Now that the cross-sectional variance and, particularly, the cross-sectional skewness of the households' consumption growth rates have been identified as important components of the SDF, it is of interest to in- 
TABLE 7

Unexplained Premium of Value Stocks over Growth Stocks

\begin{tabular}{|c|c|c|c|c|c|c|c|c|c|}
\hline \multirow[b]{2}{*}{ RRA } & \multicolumn{3}{|c|}{ SDF: EQ. (4) } & \multicolumn{3}{|c|}{ SDF: EQ. (5) } & \multicolumn{3}{|c|}{ SDF: EQ. (9) } \\
\hline & $\begin{array}{c}\text { Average } \\
\text { Unexplained } \\
\text { Premium } \\
\text { (1) }\end{array}$ & $\begin{array}{c}F \text {-Statistic } \\
p \text {-Value } \\
(2)\end{array}$ & $\begin{array}{c}F \text {-Statistic } \\
\text { Bootstrap } \\
p \text {-Value } \\
(3)\end{array}$ & $\begin{array}{c}\text { Average } \\
\text { Unexplained } \\
\text { Premium } \\
(4)\end{array}$ & $\begin{array}{c}F \text {-Statistic } \\
p \text {-Value } \\
(5)\end{array}$ & $\begin{array}{c}F \text {-Statistic } \\
\text { Bootstrap } \\
p \text {-Value } \\
(6)\end{array}$ & $\begin{array}{c}\text { Average } \\
\text { Unexplained } \\
\text { Premium } \\
(7)\end{array}$ & $\begin{array}{c}F \text {-Statistic } \\
p \text {-Value } \\
(8)\end{array}$ & $\begin{array}{c}F \text {-Statistic } \\
\text { Bootstrap } \\
p \text {-Value } \\
(9)\end{array}$ \\
\hline 0 & 1.19 & .05 & .10 & 1.19 & .05 & .10 & 1.19 & .05 & .10 \\
\hline 1 & 1.30 & .05 & .11 & 1.19 & .05 & .10 & 1.22 & .05 & .12 \\
\hline 2 & 1.67 & .05 & .11 & 1.13 & .04 & .06 & 1.26 & .05 & .09 \\
\hline 3 & 2.93 & .21 & .24 & .91 & .04 & .07 & 1.29 & .05 & .11 \\
\hline 4 & -.15 & .73 & .79 & .50 & .57 & .54 & 1.33 & .06 & .12 \\
\hline 5 & $<-10$ & .68 & .79 & -.22 & .98 & .97 & 1.38 & .06 & .12 \\
\hline 6 & $<-10$ & .63 & .77 & -1.26 & .78 & .71 & 1.43 & .07 & .11 \\
\hline 7 & $<-10$ & .59 & .75 & -2.68 & .63 & .58 & 1.48 & .08 & .12 \\
\hline 8 & $<-10$ & .56 & .75 & -4.52 & .55 & .52 & 1.54 & .08 & .12 \\
\hline 9 & $<-10$ & .54 & .73 & -6.82 & .51 & .46 & 1.61 & .09 & .15 \\
\hline
\end{tabular}

NoTE. - We calculate the unexplained premium statistic, $u$, on the basis of the SDFs given in eqq. (4), (5), and (9) over the period 1982:1-1996:1 and test the hypothesis that the unexplained premium equals zero. We report the unexplained premium on the excess return of high-both
stocks for the combined tranches. The factor time series were kindly provided by Gene Fama and Ken French. 
vestigate the comovement of these moments with macroeconomic variables.

We also tested the implications of the ubiquitous complete consumption insurance model, the "representative-consumer" model, when the limited participation of households in the capital markets is taken into account. Consistent with earlier results, we reject the model when no provision is made for the limited participation. We also presented some evidence that an SDF calculated as the per capita marginal rate of substitution is better able to explain the equity premium and does so with a lower value of the RRA coefficient as the definition of asset holders is tightened to recognize the limited participation of households in the capital market. Our evidence that the representative-consumer model can account for the equity premium when limited participation is taken into account is sensitive to the experimental design. It is of interest to explore further the robustness of this evidence.

\section{References}

Abel, Andrew B. "Asset Prices under Habit Formation and Catching Up with the Joneses." A.E.R. Papers and Proc. 80 (May 1990): 38-42.

Aiyagari, S. Rao, and Gertler, Mark. "Asset Returns with Transactions Costs and Uninsured Individual Risk.” I. Monetarv Econ. 27 (June 1991): 311-31.

Altonji, Joseph G.; Hayashi, Fumio; and Kotlikoff, Laurence J. "Is the Extended Family Altruistically Linked? Direct Tests Using Micro Data." A.E.R. 82 (December 1992): 1177-98.

Alvarez, Fernando, and Jermann, Urban J. "Efficiency, Equilibrium, and Asset Pricing with Risk of Default." Econometrica 68 (July 2000): 775-97.

Attanasio, Orazio P.; Banks, James; and Tanner, Sarah. "Asset Holding and Consumption Volatility.” L.P.E. 110 (August 2002): 771-92.

Attanasio, Orazio P., and Davis, Steven J. "Relative Wage Movements and the Distribution of Consumption." I.P.E. 104 (December 1996): 1227-62.

Attanasio, Orazio P., and Weber, Guglielmo. "Is Consumption Growth Consistent with Intertemporal Optimization? Evidence from the Consumer Expenditure Survey." I.P.E. 103 (December 1995): 1121-57.

Bansal, Ravi, and Coleman, Wilbur John, II. "A Monetary Explanation of the Equity Premium, Term Premium, and Risk-Free Rate Puzzles.” I.P.E. 104 (December 1996): 1135-71.

Basak, Suleyman, and Cuoco, Domenico. "An Equilibrium Model with Restricted Stock Market Participation.” Rev. Financial Studies 11 (Summer 1998): 309-41.

Benartzi, Shlomo, and Thaler, Richard H. "Myopic Loss Aversion and the Equity Premium Puzzle." O.J.E. 110 (February 1995): 73-92.

Bewley, Truman F. "Thoughts on Tests of the Intertemporal Asset Pricing Model." Working paper. Evanston, Ill.: Northwestern Univ., 1982.

Blume, Marshall E., and Zeldes, Stephen P. "The Structure of Stock Ownership in the U.S.” Working paper. Philadelphia: Univ. Pennsylvania, 1993.

Boldrin, Michele; Christiano, Lawrence J.; and Fisher, Jonas D. M. "Habit Persistence, Asset Returns, and the Business Cycle." A.E.R. 91 (March 2001): 149-66.

Brav, Alon, and Geczy, Christopher C. "An Empirical Resurrection of the Simple 
Consumption CAPM with Power Utility.” Working paper. Chicago: Univ. Chicago, 1995.

Campbell, John Y., and Cochrane, John H. "By Force of Habit: A ConsumptionBased Explanation of Aggregate Stock Market Behavior.” I.P.E. 107 (April 1999): 205-51.

— . "Explaining the Poor Performance of Consumption-Based Asset Pricing Models." I. Finance 55 (December 2000): 2863-78.

Cochrane, John H. “A Simple Test of Consumption Insurance.” L.P.E. 99 (October 1991): 957-76.

- "Where Is the Market Going? Uncertain Facts and Novel Theories." Fed. Reserve Bank Chicago Econ. Perspectives 21 (November-December 1997): 3-37.

Cochrane, John H., and Hansen, Lars Peter. "Asset Pricing Explorations for Macroeconomics.” In NBER Macroeconomics Annual 1992, edited by Olivier J. Blanchard and Stanley Fischer. Cambridge, Mass.: MIT Press, 1992.

Cogley, Timothy. "Idiosyncratic Risk and the Equity Premium: Evidence from the Consumer Expenditure Survey." L. Monetary Econ. 49 (March 2002): 309-34.

Constantinides, George M. "Intertemporal Asset Pricing with Heterogeneous Consumers and without Demand Aggregation." I. Bus. 55 (April 1982): 253-67.

. "Habit Formation: A Resolution of the Equity Premium Puzzle." I.P.E. 98 (June 1990): 519-43.

Constantinides, George M.; Donaldson, John B.; and Mehra, Rajnish. "Junior Can't Borrow: A New Perspective on the Equity Premium Puzzle.” O.I.E. 117 (February 2002): 269-96.

Constantinides, George M., and Duffie, Darrell. "Asset Pricing with Heterogeneous Consumers.” I.P.E. 104 (April 1996): 219-40.

Daniel, Kent, and Marshall, David. "Equity-Premium and Risk-Free-Rate Puzzles at Long Horizons." Macroeconomic Dynamics 1, no. 2 (1997): 452-84.

Danthine, Jean-Pierre; Donaldson, John B.; and Mehra, Rajnish. "The Equity Premium and the Allocation of Income Risk." I. Econ. Dynamics and Control 16 (July-October 1992): 509-32.

Epstein, Larry G., and Zin, Stanley E. "Substitution, Risk Aversion, and the Temporal Behavior of Consumption and Asset Returns: An Empirical Analysis." I.P.E. 99 (April 1991): 263-86.

Fama, Eugene F., and French, Kenneth R. "Common Risk Factors in the Returns on Stocks and Bonds." L. Financial Econ. 33 (February 1993): 3-56.

Ferson, Wayne E., and Constantinides, George M. "Habit Persistence and Durability in Aggregate Consumption: Empirical Tests.” L. Financial Econ. 29 (October 1991): 199-240.

Haliassos, Michael, and Bertaut, Carol C. "Why Do So Few Hold Stocks?" Econ. I. 105 (September 1995): 1110-29.

Hansen, Lars Peter, and Jagannathan, Ravi. "Implications of Security Market Data for Models of Dynamic Economies.” I.P.E. 99 (April 1991): 225-62.

Hansen, Lars Peter, and Singleton, Kenneth J. "Generalized Instrumental Variables Estimation of Nonlinear Rational Expectations Models.” Econometrica 50 (September 1982): 1269-86.

He, Hua, and Modest, David M. "Market Frictions and Consumption-Based Asset Pricing.” L.P.E. 103 (February 1995): 94-117.

Heaton, John, and Lucas, Deborah J. "Evaluating the Effects of Incomplete Markets on Risk Sharing and Asset Pricing." L.P.E. 104 (June 1996): 443-87. 
. "Market Frictions, Savings Behavior, and Portfolio Choice." Macroeconomic Dynamics 1, no. 1 (1997): 76-101.

." Portfolio Choice and Asset Prices: The Importance of Entrepreneurial Risk." I. Finance 55 (June 2000): 1163-98.

Jacobs, Kris. "Incomplete Markets and Security Prices: Do Asset-Pricing Puzzles Result from Aggregation Problems?” I. Finance 54 (February 1999): 123-63.

Jorion, Philippe, and Goetzmann, William N. "Global Stock Markets in the Twentieth Century.” I. Finance 54 (June 1999): 953-80.

. "The Equity Premium: It's Still a Puzzle." J. Econ. Literature 34 (March 1996): 42-71.

Krebs, Tom. "Consumption-Based Asset Pricing with Incomplete Markets." Manuscript. Providence, R.I.: Brown Univ., 2000.

Lucas, Deborah J. "Asset Pricing with Undiversifiable Risk and Short Sales Constraints: Deepening the Equity Premium Puzzle." I. Monetary Econ. 34 (December 1994): 325-41.

Luttmer, Erzo G. J. "Asset Pricing in Economies with Frictions.” Econometrica 64 (November 1996): 1439-67.

Mace, Barbara J. "Full Insurance in the Presence of Aggregate Uncertainty." I.P.E. 99 (October 1991): 928-56.

Mankiw, N. Gregory. "The Equity Premium and the Concentration of Aggregate Shocks." I. Financial Econ. 17 (September 1986): 211-19.

Mankiw, N. Gregory, and Zeldes, Stephen P. "The Consumption of Stockholders and Nonstockholders." I. Financial Econ. 29 (March 1991): 97-112.

Mehra, Rajnish, and Prescott, Edward C. "The Equity Premium: A Puzzle." I. Monetary Econ. 15 (March 1985): 145-61. 133-36.

Rietz, Thomas A. "The Equity Risk Premium: A Solution.” I. Monetary Econ. 22 (July 1988): 117-31.

Souleles, Nicholas S. "The Response of Household Consumption to Income Tax Refunds.” A.E.R. 89 (September 1999): 947-58.

Storesletten, Kjetil; Telmer, Chris I.; and Yaron, Amir. "Asset Pricing with Idiosyncratic Risk and Overlapping Generations.” Working paper. Pittsburgh: Carnegie Mellon Univ., 1999.

Telmer, Chris I. "Asset-Pricing Puzzles and Incomplete Markets.” L. Finance 48 (December 1993): 1803-32.

Vissing-Jørgensen, Annette. "Limited Asset Market Participation and the Elasticity of Intertemporal Substitution." J.P.E. 110 (August 2002): 825-53.

Weil, Philippe. "The Equity Premium Puzzle and the Risk-Free Rate Puzzle." $I$. Monetary Econ. 24 (November 1989): 401-21.

Wilson, Robert B. "The Theory of Syndicates. "Econometrica 36 (January 1968): 119-32. 